\title{
MADĪNAT QURTUUBA TRAS LA FITNA. UNA APROXIMACIÓN A TRAVÉS DE LA HISTORIOGRAFÍA
}

\author{
MADINNAT QURTUBA AFTER FITNA. AN APPROACH THROUGH THE HISTORIOGRAPHY
}

\author{
RAFAEL BLANCO GUZMÁN*
}

\begin{abstract}
Resumen: El principal propósito de este artículo es ofrecer una visión global de la Qurțuba Tardoislámica a través de la historiografía local reciente. Qurțuba era la ciudad más importante de al-Andalus en el siglo X. Tradicionalmente, la mayor parte de las investigaciones sobre la Córdoba islámica han estado fascinadas con la ciudad omeya. Esta actitud origina que muchos de los estudios sobre Qurțuba no estén interesados en el periodo Tardoislámico. Sin embargo, las últimas excavaciones arqueológicas realizadas en Córdoba durante los últimos veinte años nos están aportando una interesante información arqueológica que nos revela una nueva visión de la Córdoba Tardoislámica. Palabras clave: Qurțuba, arqueología islámica, al-Andalus, fitna, periodo tardoislámico, urbanismo islámico, excavaciones urbanas.
\end{abstract}

En todo periodo histórico ha existido una tendencia de la historiografía a emplear una serie de términos que pudieran ofrecernos, en pocas palabras, una imagen clara del contexto histórico en cuestión. Es así como, abogando por una actitud más didáctica que realista, el concepto decimonónico de arcaico, clásico y decadente ha sido aplicado a la historia, a la literatura, al arte, etc., siendo tal vez la época greco-romana la que más lo ha sufrido, y desde la que se ha ido transmitiendo a otros momentos históricos. Aún hoy, aunque superados a nivel científico estos conceptos anquilosados de formación, culmen y

\footnotetext{
* Universidad de Córdoba
}

\begin{abstract}
The main purpose of this paper is to offer a global vision of Late Islamic Qurțba through recent local historiography. Qurtuba was the most important city from al-Andalus in the X century. Traditionally, the most of the investigations about Islamic Cordoba had been fascinated with the Umayyad city. This attitude has caused that lots of studies about Qurtuba are not interested in Late Islamic period. Therefore, latest excavations made in Cordoba in the last twenty years are giving some interesting archaeological information that offers us a new vision of the Late Islamic Cordoba.

Key words: Qurțba, Islamic archaeology, al-Andalus, fitna, Late Islamic period, Islamic urbanism, urban excavations.
\end{abstract}

decadencia, siguen inmanentes en el pensamiento global, siendo muy difícil poder extirparlos definitivamente, reproduciéndose, con más frecuencia de lo comprensible, esta idea "arcaica" de la Historia de la Humanidad.

Según esta visión tradicional, el periodo que vamos a estudiar (s. XI-inicios del s. XIII) quedaría comprendido, al menos en lo que a Madinat Qurțuba se refiere, en uno de estos momentos históricos decadentes. Le antecede el siglo $\mathrm{X}$, el siglo de los califas omeyas, la Qurțba islámica por antonomasia que sucumbirá con la fitna y que entrará en una progresiva degeneración o decadencia; una línea descendente tal vez frenada durante algunos meses por el canto de cisne del primer califa almohade (Huici 2000: 205). 
Esta imagen de la Córdoba islámica dividida en tres fases: formación (Emirato Omeya), esplendor (Califato Omeya) y decadencia (desde la fitna hasta la conquista cristiana $)^{1}$, ha incidido negativamente en la atención prestada a los periodos señalados en ambos extremos de esta línea cronológica. Esto ha propiciado que el continuo referente islámico en Córdoba haya sido el califato omeya, periodo de gran trascendencia, pero que no alcanza a completar un siglo de los más de quinientos años de presencia islámica en esta ciudad.

Para observar como ha sido tratada la Córdoba posterior a la fitna, y más concretamente la tardoislámica $^{2}$, en la producción historiográfica creemos conveniente hablar, esencialmente, de dos etapas. En ambas sigue primando el elemento omeya, si bien la segunda ofrecerá un interesantísimo aporte arqueológico. La etapa primera comienza con los "pioneros", aquellos primeros investigadores que se adentran en el mundo de la arqueología andalusí cordobesa. Estos investigadores clásicos -todos ellos fallecidos ya en el siglo XX- formarán una escuela que, posteriormente será prolongada y continuada por diversos autores aún hoy en activo.

La segunda fase comienza a finales del siglo XX, especialmente desde mediados de la década de 1980 hasta nuestros días. Aunque lo omeya sigue siendo sobrevalorado, la gran cantidad de excavaciones arqueológicas urbanas que se suceden aportan una ingente información histórico-arqueológica. Desgraciadamente la mayoría no han sido publicadas ${ }^{3}$, aunque creemos que manejando los trabajos con que contamos podremos aproximarnos a una nueva imagen de la ciudad tardoislámica.

\footnotetext{
1. Estás fases no están explicitadas como tales en la historiografía, pero sí se deducen de los distintos argumentos que aportan las publicaciones centradas en el período islámico cordobés. Es decir, el emirato se entiende como un periodo de transición entre la etapa previa no-islámica y el asentamiento de los musulmanes en nuestra ciudad. Posteriormente, con el reinado de 'Abd al-Rahmān III se iniciará el califato, y con él un periodo considerado esplendoroso que se extinguirá tras la muerte de Almanzor y la posterior fitna (1009-1031). El drástico descenso con el que las fuentes tratan a Córdoba y la escasa atención mostrada por la bibliografía respecto a este período tardoislámico cordobés, han propiciado que, de una forma más o menos velada, se descuide este periodo en las distintas investigaciones que analizan la Córdoba islámica. Así, se entiende esta época como decadente y de poca importancia, un simple declive de la gran urbe califal

2. Con el término tardoislámico nos referimos en Córdoba a los períodos almorávide y almohade (1091-1236). A este respecto véase nuestra definición crono-terminológica en Blanco Guzmán (2008).

3. Este es un problema no exclusivo de Córdoba (Cfr. Rodríguez Temiño 2006).
}

\section{PRIMERA ETAPA: LOS PRIMEROS ESTUDIOS}

El interés por el mundo islámico en España remonta sus orígenes al siglo XVIII, pero no será hasta mediados del XIX cuando adquiera un mayor impulso, empujado por el estereotipo romántico. Mientras la España decimonónica se convierte en un referente de literatos y artistas extranjeros que buscan en ella la esencia de su pasado oriental, se van dando algunos pasos en positivo para la investigación del mundo andalusí. En este sentido será crucial, a mediados del siglo XIX, la creación de la primera cátedra de árabe en la Universidad de Madrid, que ocupará el Prof. Gayangos desde 1845 (Cabanelas 1989: 23). Gayangos será sucedido por Francisco Codera, quien consolidará bajo su sombra toda una escuela de arabistas: los "Beni Codera" (Beccaria 1999: 216).

De la influencia de Codera surgen esencialmente las figuras de don Miguel Asín Palacios, que sucederá al maestro en su cátedra, y don Julián Ribera y Tarragó (Beccaria 1999: 216), que regresará a Madrid tras un periodo encargado de la cátedra de árabe de Zaragoza (Cabanelas 1989: 25).

El arabista que más nos interesa de esta escuela madrileña de los "Beni Codera" es don Emilio García Gómez. Su actividad profesional fue prolija y fructífera. En 1932 cofunda con don Miguel Asín la Escuela de Estudios Árabes, con dos sedes: una en Madrid y otra en Granada. Esta última la dirigía el propio García Gómez y la ubicó en la "Casa del Chapiz" (Beccaria 1999: 223). En 1933 funda la revista Al-Andalus, asumiendo también su dirección -compartida con Asín hasta su muerte en 1944- durante sus 45 años de vida (Beccaria 1999: 223).

$\mathrm{Su}$ obra es esencialmente filológica. Buen traductor e intérprete de los escritos islámicos, muestra sus habilidades en el estudio de poetas esenciales del mundo medieval andalusí como Ibn Quzman (Ibn Quzman, García-Gómez 1972) o Ibn Hazm (Ibn Hazm, GarcíaGómez 1971). La obra de García Gómez va mucho más allá del mero estudio literario, en numerosos títulos deja claro su marcado interés por la investigación histórica de Madinat Qurțba (Cfr. García Gómez 1947, 1965, 1967), con una cierta preferencia por lo omeya, aunque también interesándose por el periodo taifa ${ }^{4}$.

4. Es justo comentar que, aunque centrado en el siglo $\mathrm{X}$ y XI -lo usual en la investigación tradicional andalusí, especialmente en Qurțba- don Emilio percibía ya a mediados del siglo XX cómo se estaban desatendiendo historiográficamente importantes "eslabones" en el discurso histórico del Islam andalusí. En este sentido es muy elocuente la nota preliminar en el prólogo del Tomo V de la Historia de España de don Ramón Menéndez Pidal (Lévi-Provençal 1965: 14). 
La figura de don Emilio García es crucial en el nacer de esta investigación histórica-arqueológica. Actúa como nexo entre el núcleo más puramente arabista o filológico de la "escuela madrileña", y entre aquéllos más interesados por el conocimiento histórico-arqueológico de Al-Andalus medieval. Buena muestra de ello fue su férrea amistad con E. Lévi-Provençal o con el propio Torres Balbás.

El investigador francés mantuvo una estrecha relación con García Gómez, siendo éste traductor y/o coautor de muchas de sus obras. De esta fructífera colaboración surgen interesantes obras, aún hoy esenciales. La publicación del tratado de hisba de Ibn Abdūn (García Gómez, Lévi Provençal 1992), centrado en la Sevilla almorávide, será el punto de partida que llevará a posteriores colaboraciones con el arabista francés ${ }^{5}$. También centrada en época posterior a la fitna destaca la publicación de Las Memorias de 'Abd Allah, último rey zirī de Granada (García Gómez, Lévi Provençal 1980). La obra cumbre de Lévi Provençal serán los tomos IV y V de la Historia de España dirigida por don Ramón Menéndez Pidal (Lévi Provençal 1950; 1965). La traducción la realiza García Gómez, que a su vez escribe la introducción al tomo IV y una Nota preliminar en el tomo V. Ya en esta introducción, además de ensalzar la figura de su amigo E. Lévi Provençal, resalta el califato cordobés como el momento de mayor esplendor. En la nota preliminar del Tomo V, además de un afectuoso recuerdo a su amigo, ya fallecido en 1956, vuelve a llamar la atención sobre la importancia del Califato Omeya de Córdoba (Lévi Provençal 1965: 8).

Cuatro años después que Lévi Provençal, en 1960, morirá don Leopoldo Torres Balbas. Este gran investigador y pionero de la arqueología andalusí también compartió amistad con don Emilio García Gómez. Ambos coincidieron en Granada, desde 1930 hasta 1936, fecha en la que don Emilio debe marchar a Madrid para incorporarse a la cátedra de Lengua Arábiga. Aunque arquitecto de profesión, siempre mantuvo un fuerte interés por la arqueología medieval, especialmente a partir de abril de 1923, fecha en la que es nombrado arquitecto conservador de la Alhambra (Cabanelas 1989: 26). La amistad de Torres Balbás con García Gómez le hace proponerle la inclusión en Al-Andalus de una “Crónica arqueológica de la España musulmana”. La primera "Crónica" se publica en 1934 y se prolongará

5. Así lo aclara el propio García Gómez: “... he iniciado con el gran sabio francés un extenso plan de labor conjunta, que irá desde las simples versiones o adaptaciones, como ésta o la del tomo primero de su monumental Historia de la España Musulmana, a punto de aparecer en castellano, hasta ediciones criticas y otras empresas futuras de considerable volumen" (Beccaria 1999: 254). en números sucesivos hasta la muerte del propio Torres-Balbás. Según el texto inaugural, Torres Balbás iba a intentar con estas publicaciones solucionar "la falta de publicidad, al insertar en ella el resultado de los estudios, excavaciones y hallazgos realizados en los últimos años" (Ocaña 1989: 62). La obra de Torres Balbás es de temática muy variada, pudiéndose extraer de ella aspectos concretos de Madīnat Qurțba, aunque casi siempre referidos más a época omeya que tardoislámica (Torres Balbás 1957, 1985). Su obra, aunque carece del conocimiento arqueológico que hoy día poseemos, se presenta como una espléndida síntesis del mundo andalusí basada en la lectura de los restos arqueológicos disponibles y en la interpretación de las fuentes escritas, como realiza, por citar algunos ejemplos, con las murallas de la Axerquía ${ }^{6}$ (Torres Balbás 1985: 479-481) o con los baños de la C/ Comedias (Torres Balbás 1985: 177).

Junto a estos investigadores, cuyo trabajo es más global y aglutinador, coinciden una serie de autores locales. Curiosamente, el primer título referido a la Córdoba islámica vendrá de manos de don Rafael Castejón y Martínez de Arizala, emérito profesor de la Escuela de Veterinaria de Córdoba. Su pasión por el pasado andalusí cordobés le hizo escribir, ya a inicios del siglo XX, una visión de la Córdoba califal con base en las fuentes existentes (Castejón 1929). En su trayectoria como estudioso de la Córdoba islámica -que alterna con sus trabajos sobre veterinaria (Cfr. VV.AA. 1964)- analiza, especialmente, el período califal (Cfr. Castejón 1963; 1965), siendo el punto central de atención los grandes restos visibles del pasado omeya: la Mezquita aljama (Castejón 1945; 1971) y Madinnat alZahrā' (Castejón 1976).

Estos mismos elementos serán los que tomen mayor trascendencia en la obra de don Félix Hernández Giménez, aunque en este caso acompañados de importantes actuaciones arqueológicas en los mismos (Cfr. Fernández Puertas 1974-1975; Vicent 1975). Será este arquitecto-conservador catalán, encargado de la zona IV del Tesoro Artístico de España (Vallvé 1990: 536), quien lleve acabo, a partir de 1920, importantísimas excavaciones arqueológicas en Madinat al-Zahrā' (Hernández 1985) y en la propia Mezquita de Córdoba (Hernández 1975) ${ }^{7}$. Por desgracia su obra es excesivamente

6. Actualmente, gracias a las excavaciones realizadas a finales del siglo XX, sabemos que el alzado de tapial pertenece a época bajomedieval cristiana y que, aunque sigue un trayecto similar al islámico, no siempre coincide con éste (Córdoba, Marfil 1995: 147-151)

7. Esta excavación en el subsuelo de la Mezquita-Catedral de Córdoba fue supervisada en 1931 por su compañero Torres Balbás a instancias de la Dirección General de Bellas Artes, que le pide un 
parca, más aún si consideramos la gran cantidad de información arqueológica que debió manejar en tantos años de estudio. Además, como sucede con Castejón, los períodos posteriores a la fitna son obviados.

En la Mezquita trabajaba desde 1927 bajo la dirección de Hernández un joven delineante: Manuel Ocaña Jiménez. Junto a don Félix se había formado en planimetría, excavaciones y clasificación y recomposición de materiales arqueológicos (Ocaña 1989: 57). Atraído por el mundo andalusí, muestra pronto muy buenas actitudes para la epigrafía islámica y seguirá aumentando su formación en Granada, a partir de 1932, en la Escuela de Estudios Árabes que dirige García Gómez. Sus estudios en la "Casa del Chapiz" los va alternando con su trabajo en la Alhambra bajo las órdenes de Torres Balbás (Ocaña 1989: 57; Vallvé 1990: 538). Para completar su formación, marcha a Madrid en 1940, sumergiéndose en el ambiente de la Escuela de Asín y Ribera. Regresará definitivamente a Córdoba en $1956^{8}$. La obra de Ocaña se considera aún hoy esencial en la historiografía cordobesa. Al igual que sucede con Félix Hernández y Castejón, Madīnat al-Zahrā' (Ocaña 1988-1990) y la Mezquita aljama (Ocaña 1986) serán temas preponderantes, si bien no únicos. Entre otros aspectos, estudiará también las puertas y murallas de la ciudad (Ocaña 1935; 1982). A nivel local sus aportaciones fueron muy variadas $^{9}$, aunque, como sucede con todos los investigadores que estamos viendo, el periodo califal omeya sigue predominando de forma contundente (Ocaña 1976). Aún así, no fina en él sus intereses científicos (Cfr. Ocaña $1963 ; 1975 ; 1990)$. Fuera de esta ciudad su obra sigue cargada de gran prestigio y calidad, especialmente en temas epigráficos (Cfr. Ocaña 1964; 1970).

Por último, no debemos olvidar la figura de don Samuel de los Santos Gener. A diferencia de los otros investigadores comentados, don Samuel no mostró

informe de peligrosidad de las excavaciones que se estaban realizando. Don Leopoldo no pudo menos que elogiar la labor restauradora de don Félix Hernández (Ocaña 1989: 57; Vallvé 1990: 537).

8. Durante todo este tiempo Ocaña intercala sus estudios islámicos con su trabajo como técnico proyectista en CENEMESA hasta su jubilación en 1979. La estancia en Madrid viene favorecida por el traslado otorgado por su empresa. En 1956 la empresa lo destina definitivamente a su factoría cordobesa (Vallvé 1990: 539). En Córdoba alternará su trabajo en CENEMESA con cargos docentes, primero en el Centro de Estudios Superiores Universitarios - a partir de 1968- y luego en el Colegio Universitario de Córdoba (1971-1975) como Profesor de Lengua y Literatura Árabes. Finalmente, este cargo le será confirmado en la nueva Universidad de Córdoba hasta su jubilación profesional en 1979 (Cfr. Vallvé 1990: 539).

9. Cabe reseñar como, incluso, efectúa en febrero de 1961, a iniciativa del Ayuntamiento de Córdoba, unas excavaciones en el Pago de Tejavana buscando la localización de Madīnat al-Zāhira (Vallvé 1990: 544) nunca una gran atención por el mundo andalusí (Santos Gener 1950; Miranda 2004). Aun así, decidimos incluirlo porque recoge gran cantidad de información arqueológica recopilada a mediados del siglo XX en Córdoba. Santos Gener documenta los hallazgos realizados en excavaciones urbanas de una forma más que meritoria (Santos Gener 1955), ya que si bien su documentación no muestra una exhaustividad y un rigor científico que permita asegurar la datación estratigráfica de los restos inventariados, nos ha transmitido una valiosa información elaborada en unas condiciones muy precarias ${ }^{10}$. Su obra es un catálogo o inventario en el que se recoge una serie de hallazgos o restos exhumados, y que aún hoy es utilizado por los investigadores para fundamentar diversas hipótesis y teorías.

Así pues, descartando a Santos Gener, podemos hablar de tres grandes figuras en la historiografía tradicional de la Córdoba andalusí: Castejón, Hernández y Ocaña. Castejón fue veterinario de profesión, Hernández arquitecto restaurador y Ocaña ingeniero proyectista. La obra más fecunda es, sin duda, la de Ocaña. Don Félix Hernández, si bien fue muy activo arqueológicamente, bibliográficamente no fue tan prolífico. Por su parte, Castejón tuvo que compaginar su pasión por lo andalusí con su labor como profesor de veterinaria.

De todas formas, cuando cualquiera de ellos centraba su labor en la Córdoba islámica decidían otorgar una mayor preferencia al período omeya y, especialmente, al califal. Es algo lógico y comprensible en los inicios de la investigación. Así como en Granada llamaba más la atención el periodo nazarí, o en Sevilla atraía más el almohade, de Córdoba deslumbra el esplendor de los califas omeyas. Ello trae como consecuencia que los períodos previos y, sobre todo, el final, quedaran eclipsados, o vagamente tratados, en sus estudios.

\section{SEGUNDA ETAPA: LA PRODUCCIÓN HISTORIOGRÁFICA RECIENTE}

Sin embargo, esta escasez de estudios sobre el período islámico posterior a la fitna seguirá manteniéndose en investigadores de la segunda etapa. La Qurțba omeya seguirá siendo, hasta hoy, el punto de referencia básico dentro de la ciudad islámica.

10. Don Samuel no pudo realizar excavaciones, tuvo que limitarse a los seguimientos de las distintas obras, intentando recoger en su cuaderno todas aquellas páginas de la historia que estaban siendo "quemadas" ante sus ojos. Gracias a su labor hoy podemos tener una cierta noción de aquella información arqueológica desaparecida, siendo imposible su estudio en profundidad más allá de la propia información aportada por Don Samuel. 
En este sentido, los trabajos de Rafael Castejón (1929, 1963 y 1965), Lévi Provençal (1957) o Emilio García Gómez (1965) de mediados del siglo XX han sido revisados y actualizados por distintos autores como Emilio Cabrera (1994; 1998) o Basilio Pavón (1988a; 1988b), que en modo alguno han modificado la línea marcada por aquéllos. En otro punto está el trabajo de autores como Valdés (2004) que revitaliza la obra clásica de Ocaña (1965), introduciendo las novedades arqueológicas que no pudo integrar en su trabajo el autor cordobés, y orientando las palabras de $\mathrm{Ibn}$ Hazm según el conocimiento arqueológico acumulado en los últimos años. Mención aparte requiere la prolífica obra de Antonio Arjona. Este autor, aunque recopila interesantes datos extraídos de las fuentes escritas con una valiosa información topográfica sobre la Qurțba omeya (Arjona 1989), también se aventura a pronosticar, sin una correcta base arqueológica -ya existente en la fecha en que redacta-, la ubicación de determinados edificios islámicos (Arjona 1999; 2000a; 2000b; 2002; 2003b; 2003c; 2004a; 2004b) ${ }^{11}$.

A pesar de que sigue manteniéndose, incluso en esta segunda etapa, ese interés desmedido por el siglo $\mathrm{X}^{12}$, contamos con la obra de Jesús Zanón (1989) como el único estudio global y sintético que nos permite aproximarnos a la Qurțba tardoislámica. Realiza un interesante análisis de las fuentes para argüir su recorrido por la "oscura" Córdoba almohade. El minucioso estudio del urbanismo tardoislámico de Zanón se plasma en una obra ágil y completa, base imprescindible para cualquier investigación que se pretenda realizar para esta época en Córdoba. Aunque se centra en el periodo almohade, incluye en su estudio un gran número de fuentes árabes referidas al periodo califal, imprimiéndoles un nuevo sesgo interpretativo con el que intenta completar el notable vacío de conocimientos sobre los últimos años de dominio islámico en Qurțuba. Los cronistas más empleados son Ibn Baškuwāl, Ibn al-Jatib, al-Idrisī y al-Udri. La escasez de datos en estas fuentes para el periodo tardoislámico hace que Zanón remita continuamente a lo que estos autores nos cuentan de la Córdoba omeya califal, adaptándolo a lo que se conoce - o se conocía en 1989- de la ciudad tardoislámica, apoyándose para ello en algunos trabajos previos, muy generales, como los de J. Vallvé (1986) o Antonio

11. Publica también, en la misma línea, una serie de trabajos que intentan ofrecer una visión sintética del urbanismo islámico (Arjona 1999; 2000; 2000d; 2002a; 2002b; 2003a; 2004a; Arjona y López 2000) asignando nombres y localizaciones posibles a los arrabales occidentales (Arjona 2000d) y orientales (Arjona 2004a).

12. A excepción de algunos artículos de Arjona que estudian la topografía de la Córdoba posterior a la fitna (Arjona 1998; 2004a; 2004c).
Almagro (1987: 424-426), y en los ya comentados de Torres Balbás (1957; 1985) y Ocaña (1935), en los que de forma sucinta se ofrecen algunos datos topográficos de la Qurțba tardoislámica. La información que recoge para Córdoba es así, en su mayor parte, referida a época califal, ya que, como ya hemos apuntado, para el periodo almorávide-almohade la atención de las fuentes escritas, aunque traten de una forma secundaria la ciudad de Córdoba (Huici 2000: 205-209), se centran en otras ciudades (Huici 1969; 2000; García Gómez y Lèvi Provençal 1992).

Los datos que podemos obtener de Zanón, unidos a la información que nos transmiten las fuentes posteriores a la conquista cristiana y que recoge, entre otros, Escobar (Cfr. 1989, 2000, 2003, 2006) nos permiten acotar a través de las fuentes escritas el periodo tardoislámico. Contamos, por tanto, con un antes y un después que nos informa sobre aquello que sirve de base a la ciudad tardoislámica y sobre lo que queda de ella tras su crepúsculo. Estos escasos datos escritos recopilados e interpretados por Zanón y Escobar pueden completarse y acrecentarse con datos directos de época tardoislámica: los restos arqueológicos documentados a partir de las distintas excavaciones acometidas en el subsuelo de Córdoba desde mediados de los años ochenta.

Aunque Córdoba ha sufrido graves problemas con la gestión del patrimonio arqueológico en el tercer cuarto del siglo XX, especialmente en la zona de la Medina islámica (Acién y Vallejo 1998: 122); desde finales del siglo XX, una vez superada la polémica excavación de Cercadilla en 1991, surge una nueva mentalidad y criterio urbanizador, junto al aumento de las excavaciones en las zonas extramuros occidental, septentrional y meridional (Acién y Vallejo 1998: 127 y ss.). Todo ello redundará en el incremento del conocimiento que hasta entonces teníamos de la ciudad islámica (Castro del Río 2001; 2005; Fuertes 1997; 2002; Acién y Vallejo 1998; Muri1lo, Casal y Castro del Río 2004). Pero, sobre todo, se revela una nueva ciudad tardoislámica, distinta a la que se intuía desde el análisis de las fuentes escritas. Hasta esta segunda etapa historiográfica lo tardoislámico había quedado marginado. Ahora, aunque todavía en un lugar muy secundario, empieza a tomar fuerza. Lo tardoislámico quedará tocado, aunque muy levemente, en algunos trabajos que ofrecen un rápido recorrido arqueológico por la ciudad de Córdoba (Murillo et alii 1997), por sus murallas (Escudero et alii 1999), por la arquitectura doméstica (Murillo, Fuertes y Luna 1999), o centrados en una zona muy precisa de la ciudad: el Conjunto Arqueológico de Cercadilla (Fuertes 2006; Hidalgo y Fuertes 2001) o las excavaciones realizadas en el Palacio de Orive (Murillo et alii 1995; Ruiz et alii 2003). 
Sin duda alguna los elementos fortificados han sido los que más trato han recibido para época tardoislámica. Como es propio en una ciudad andalusí que ya no goza de la estabilidad del siglo X y que sufre continuas incursiones cristianas y disturbios internos, los elementos defensivos toman un papel preponderante, como muestran los restos que aún hoy conservamos del recinto amurallado de la Axerquía (Escudero et alii 1999: 210-212). En época islámica se amplia el antiguo recinto de la Medina-continuación del romano imperial- con una cerca que rodea parte de los arrabales orientales de la ciudad, los más próximos al lienzo este de la Madīna. La historiografía cordobesa durante muchos años no ha tenido certeza absoluta sobre la posible datación de esta cerca, originando una amplia polémica en la que unos autores hablan de un origen taifa (Zanón 1989: 53) y otros retrasan su construcción a época almorávide (Torres Balbás 1985: 479-481). Ambas posturas encuentran su refrendo o negación en las fuentes escritas y en las distintas excavaciones realizadas a finales del siglo XX e inicios del actual. El origen almorávide se relacionaba con el impuesto que establece 'Ali b. Yūsuf en 1125 para reforzar las cercas de las principales ciudades de al-Andalus y el Magreb (Torres Balbás 1985b: 479-481). Arqueológicamente, constataron esta cronología distintas excavaciones realizadas tanto en la zona Norte (Baena 1990; 1991; Baena y Marfil 1988-90), Este (Córdoba y Marfil 1995; Marfil 1997) y Sur (Rodero et alii 2003; González, Rodero y Murillo 2003) de la cerca. Sin embargo, excavaciones realizadas en la Puerta de Baeza han sacado a la luz los restos de una puerta con torres del siglo XI (Morena 2002; Bermúdez 2005), junto a un lienzo murario de la misma fecha. Adosado a la cerca del XI se documentó otro lienzo del XII y, tras éste, uno bajomedieval cristiano (Bermúdez 2005). Estos hallazgos desmontan la hipótesis de una génesis almorávide, apoyando la teoría de Zanón (1989, 53-55) que opta por datar su origen en los primeros años de la fitna y en el posterior periodo taifa ${ }^{13}$. De este modo sabemos que, al menos en el ángulo suroriental de la Axerquía hubo ya un recinto amurallado en el siglo XI.

Junto a la muralla de al-Rabaḍ al-Šarquī se han datado en época tardoislámica otros dos recintos fortificados, concretamente de época almohade: el Castillo Viejo de la Judería y el recinto que rodeaba a la torre de

13. Esta teoría se apoya en Al-Maqqari quien nos dice, refiriéndose a los arrabales, que durante la fitna se cava un foso delimitando parte de ellos y levantando una muralla defensiva (Zanón 1989: 54). Así mismo, estas murallas se verían afectadas por las remodelaciones realizadas en época Taifa bajo el mandato de Muhammad b. Yahwar y tras la conquista de Córdoba por parte de al-Mu 'tamid (Zanón 1989: 22-23). la Calahorra. Este último, además de su función defensiva, estaría destinado a albergar al ejército a la espera de próximas batallas con el norte cristiano (León et alii 2004: 254-255). El llamado Castillo Viejo de la Judería, en el actual barrio de San Basilio, ocupa un espacio extramuros de la ciudad junto al límite Suroeste del recinto de la Medina. Define un espacio rectangular con torres en los ángulos y en el centro de cada lienzo. Actualmente sólo se conservan los lienzos Norte y Oeste y cuatro torres de planta cuadrada (Córdoba 2003-2004: 128). Aunque algunos autores adscriben estos restos a época almorávide (Pavón 1988a: 175), el tipo de tapia, así como una posible puerta en recodo (Torre de Belén) nos estarían confirmando la génesis almohade de esta obra (Córdoba 2003-2004: 128).

Este interés fortificador de época tardoislámica, lógico dentro de un contexto de inseguridad e inestabilidad con continuas algaras cristianas (Escudero et alii 1999: 211), se da junto a una revitalización del hábitat doméstico en época tardoislámica. Al menos esta es la imagen que podrían ofrecernos las excavaciones efectuadas en el Palacio de Orive (Murillo et alii 1995; Ruiz et alii 2003), dentro de las murallas de la Axerquía y próximas a la Madinnat al-Attiqa. En el solar que perteneciera al antiguo convento de San Pablo se realizaron varias campañas de excavación a partir de 1992 que sacaron a la luz interesantes restos tardoislámicos datados entre el siglo XII y principios del XIII. En esta zona se documentaron, según sus excavadores, unas 12 casas, con interesantes zócalos decorados con formas geométricas (García y Medina 2001). La calidad y amplitud de las casas permiten asociarlas a una clase social elevada (Murillo et alii 1995; Ruiz Lara et alii 2003).

A extramuros también parece existir una cierta revitalización del hábitat doméstico, especialmente hacia el Oeste y Norte. En este sentido podemos atender a las investigaciones realizadas en la Zona Arqueológica de Cercadilla (Fuertes 2006; Hidalgo y Fuertes 2001) y en su entorno inmediato (Murillo et alii 2003; Ruiz Nieto 2003). En toda esta zona, como en todo el ŷanib algarbī, según muestran tanto las fuentes literarias como los últimos trabajos arqueológicos, se produce tras la fitna un drástico cese del hábitat. Pocos años después se realizará una "reocupación selectiva" de los espacios domésticos califales (Ruiz Nieto 2003: 399), patente, por ejemplo, en las reparaciones de pavimentos y en las reestructuraciones de la red de evacuación de aguas residuales. Estos restos domésticos tardoislámicos aparecen a menudo vinculados a un área industrial, como muestran las estructuras que evidencian la dedicación en esta zona a tareas alfareras (Fuertes e 
Hidalgo 2001: 173; Fuertes 2006: 458 y 459), metalúrgicas (Murillo et alii 2003: 372) y caleras (Ruiz Nieto 2003: 399) aunque no con la densidad e intensidad de época califal, y tal vez unidos al trabajo agrícola del entorno (Fuertes 2006: 458-459; Ruiz Nieto 2003: 299).

Al Este de Cercadilla, hacia el Norte de los recintos amurallados, se documentaron restos domésticos asociados a un cementerio: la Maqbarat Umm Salama (Botella et alii 2005). En esta misma zona septentrional, con motivo de las obras realizadas para la construcción de los aparcamientos del Vial Norte, se registra, junto con los restos de una posible almunia califal -siglos X e inicios del XI- y de parte de un arrabal nacido en su entorno, una reocupación doméstica del solar de época almohade. El nuevo hábitat se instala en la zona tras un periodo de abandono y saqueo posterior a la fitna. Tal y como hemos comentado para los arrabales occidentales, aquí también se superponen las estructuras tardoislámicas a los antiguos muros que ya habían sido expoliados y colmatados (Ventura et alii 2003: 341), intercalándose los espacios domésticos con espacios industriales, como evidencian los restos de producción cerámica tardoislámica (Ventura et alii 2003: 338, 341 y 342; Murillo et alii 2003: 360).

Al Noreste del Vial Norte, en la Calle Santa Rosa, también se ha constatado la aparición de restos tardoislámicos; en este caso sobre una almunia califal próxima al cauce de un arroyo (Ruiz Nieto 2001). El núcleo habitacional se desarrollaría en torno a una gran estructura rectangular, interpretada como una posible mezquita por su planta y tipología constructiva, aunque solo se ha conservado la primera hilada de su cimentación (Ruiz Nieto 2001: 223).

\section{HACIA UNA TERCERA ETAPA}

Consideramos que, con los datos arqueológicos publicados que hoy disponemos, utilizar la palabra "decadencia" como algo global, como algo generalizado a todos los aspectos de la vida y a todas las épocas y culturas que forman este dilatado periodo de tiempo, que tan poco conocemos, es poco práctico.

Aunque ya empieza a mostrarse lo tardoislámico en la historiografía cordobesa aún hoy, inmersos en la segunda etapa, no existen obras que pretendan dar una visión arqueológica clara, completa y de conjunto de un periodo hasta ahora cubierto por una espesa cortina de humo iniciada en el crepitar de una Qurțba omeya que se extingue violentamente entre las llamas de la fitna y que, quizás, podamos disipar con la información arqueológica con la que hoy contamos.
Queremos creer que, tras esta segunda etapa en la que la historiografía, gracias a los nuevos datos arqueológicos, empieza a mostrar tímidamente la Qurțba posterior a la fitna, pronto nos veremos inmersos en una productiva tercera etapa en la que, por fin, se atienda a esta época como es debido. Y creemos que esta tercera etapa está cada vez más próxima. La historiografía actual no debe permanecer muda por más tiempo ante la evidencia arqueológica.

\section{POST SCRIPTUM}

Recientemente, a finales de 2008, han visto la luz algunas publicaciones que, tal vez, sean los primeros pasos en esa tercera etapa a la que aludimos. En este sentido, toma importancia el trabajo de A. León, E. León y J.F. Murillo publicado en el $4^{\circ}$ Congreso Internacional sobre Fortificaciones celebrado en Alcalá de Guadaíra, en el que se trata el desarrollo diacrónico de las fortificaciones cordobesas próximas al río Guadalquivir. Asimismo, consideramos de gran trascendencia el primer número de la revista Anejos de Anales de Arqueología Cordobesa en el que se publica distinta información arqueológica de la Córdoba tardoislámica recogida en excavaciones realizadas durante los últimos años. De esta revista podríamos destacar, entre otros, los trabajos de E. León y E. Castro del Río o de E. Salinas y M.C. Méndez que nos ofrecen una muestra de la ocupación tardoislámica en los sectores extramuros Norte y Este. En esta misma línea se mueve nuestro artículo sobre la arquitectura doméstica tardoislámica, en este caso centrado en la zona intramuros de la Axerquía (véase Nota 2).

\section{BIBLIOGRAFÍA}

ACIÉN ALMANSA, M. y VALLEJO TRIANO, A. (1998): "Urbanismo y Estado Islámico. De Corduba a Qurțba - Madinat al-Zahrā",, en P. Cressier y M. García Bernal (eds.), Genèse de la ville islamique en Al-Andalus et au Maghreb Occidental: 107-136. Madrid.

ALMAGRO, A. (1987): "Planimetría de las ciudades hispanomusulmanas", Al-Qantara VIII: 421-448.

ARJONA CASTRO, A. (1989): Anales de Córdoba musulmana (711-1008). Córdoba.

- (1998): “Averroes, el médico", BRAC 135: 111-126.

- (1999): "Nuevas aportaciones a la topografía de la Córdoba islámica y de su Mezquita Aljama”, BRAC 137: 169-182. 
- (2000a): "Hacia una nueva visión histórica de la Córdoba Islámica", Arbor: Ciencia, pensamiento y cultura 654: 175-190.

- (2000b): "La Almunia "Al Rusâfa" en el yacimiento arqueológico de Turruñuelos", BRAC 138: 153-184.

- (2000c): "La judería en la Córdoba del emirato y califato", Anaquel de estudios árabes 11: 101-108.

- (2000d): "Topografía de cinco arrabales de la Córdoba islámica", BRAC 139: 95-114.

- (2002): "Topografía e historia del Alcázar omeya de Córdoba y su entorno inmediato (II)", BRAC 142: $325-340$.

- (2003a): "Aproximación a la topografía de la Córdoba islámica”, en Andalucía medieval: actas del III Congreso de Historia de Andalucía, Córdoba, 2001, Vol. 6: 29-74.

- (2003b): "Sobre la localización de la iglesia de San Acisclo y del Fash al Suradiq (campamento militar de la Córdoba islámica)", BRAC 144: 161-172.

- (2003c): “Toponimia de Córdoba islámica: el Cerro de Abu' Abda, hoy colina del Parque Cruz Conde y el itinerario de Al-Razi a través de Córdoba en el año 972", BRAC 145: 171-176.

- (2004a): 'El cementerio de los Banu-1-'Abbas de Córdoba, el molino de Banu-l-'Abbas (de Martos) y los arrabales orientales de la Córdoba islámica", BRAC 146: 203-214.

- (2004b): "Posible localización de los restos arqueológicos del Dar al-Tiraz (Casa de tiráz) en Córdoba musulmana", BRAC 147: 137-146.

- (2004c): "Un crimen en el barrio de la Ajerquia en la Córdoba del siglo XI", Codex: boletín de la Ilustre Sociedad Andaluza de Estudios Histórico-Jurídicos 1: 15-20.

ARJONA CASTRO, A. y FROCHOSO, R. (2002): "Localización del lugar donde estuvo ubicada la casa de la moneda (Dar-Al-Sikka) en la Córdoba islámica" BRAC 143: 181-198.

ARJONA CASTRO, A. y LÓPEZ, J.L. (2002): “Topografía e historia del alcázar omeya de Córdoba y su entorno inmediato (I)", BRAC 141: 153-176.

BAENA ALCÁNTARA, M.D. (1990): “I.A.U. en Avda. de las Ollerías $n^{\circ} 2$, recayente a Plaza de la Lagunilla (Córdoba). Restos de muralla de la Ajarquía”, Anuario Arqueológico de Andalucía 1987, III/Actividades de urgencia: 151-158.

- (1991): "Intervención arqueológica de urgencia en Avda. de las Ollerías n ${ }^{\circ} 14,1^{\mathrm{a}}$ fase (Córdoba)", Anuario Arqueológico de Andalucía 1989, III/Actividades de urgencia: 138-145.

BAENAALCÁNTARA, M.D. y MARFIL, P. (1988-90): "Nuevos datos acerca del amurallamiento norte de la Ajerquía cordobesa. Excavaciones arqueológicas en el n ${ }^{\circ} 14$ de la Avenida de las Ollerías (Cordoba)", Cuadernos de Madīnat al-Zahrā' 2: 165-180.

BECCARIA, L. (1999): "Bibliografía de don Emilio García Gómez”, BRAH CXCVI-C 2: 209-260.

BERMÚDEZ, J.M. (2005): "La Puerta de Baeza en la cerca de la Ajerquía cordobesa", Anuario Arqueológico de Andalucía 2002, III/Actividades de urgencia: 333-349.

BLANCO GUZMÁN, R. (2008): “Algunas precisiones sobre la Qurțba tardoislámica. Una mirada a la arquitectura doméstica de al-Rabaḍ al Šarqu $\vec{\imath}$, Anales de Arqueología Córdobesa 19: 293-322.

BOTELLA, D et alii (2005): "Evidencias arqueológicas de un cementerio andalusí en Córdoba ¿La $\mathrm{Ma}$ qbara Umm Salama?", Boletín de Arqueología Medieval 12: 19-50.

CABANELAS, D. (1989): “Torres Balbás y los estudios islámicos en la España de su época”, Cuadernos de la Alhambra 25: 23-32.

CABRERA, E. (1994): “Ornato del mundo", Córdoba Capital, vol. 1: 113-128. Córdoba.

- (1998): “Aproximación a la imagen de la Córdoba islámica", Historia, instituciones, documentos 25: 73-94.

CASTEJÓN Y MARTÍNEZ DE ARIZALA, R. (1929): "Córdoba califal", Boletín de la Real Academia de Córdoba 25: 213-228.

- (1945): La portada de Mohamed I (Puerta de San Esteban) en la gran mezquita de Córdoba. Córdoba.

- (1963): "Nuevas Identificaciones en la topografía de la Córdoba califal", I Congreso Internacional de Estudios árabes: 371-389. Córdoba.

- (1965): "Excavaciones en Córdoba para localizar las tumbas de los califas", NAH 7: 229-235.

- (1971): La Mezquita de Córdoba. León.

- (1976): Madina Azahara. La ciudad palatina de los califas de Córdoba. León.

CASTRO DEL RÍO, E. (2001): "La arquitectura doméstica en los arrabales de la Córdoba califal: la Zona Arqueológica de Cercadilla", AAC 12: 241-281.

- (2005): El arrabal de época califal de la zona arqueológica de Cercadilla: la arquitectura doméstica. Córdoba.

CÓRDOBA DE LA LLAVE, R. (2003-2004): "Fortificaciones Almohades en la provincia de Córdoba", en A. Torremocha (coord.), Los almohades: 123-129.

CÓRDOBA DE LA LLAVE, R. y MARFIL RUIZ, P. (1995): “Aportaciones al estudio de las murallas medievales de Córdoba. Estructura y técnicas de construcción en el Sector Ronda del Marrubial", Meridies 2: 145-177. 
ESCOBAR CAMACHO, J.M. (1989): Córdoba en la Baja Edad Media: Evolución Urbana de la Ciudad. Córdoba.

- (2000): “Córdoba en la Baja Edad Media: la red viaria de una ciudad mudéjar", BRAC 138: 9-56.

- (2003): "La imagen de una ciudad a fines de la Edad Media: Córdoba en al época del Gran Capitán”, en Córdoba, el Gran Capitán y su época: 15 y ss.

- (2006): "De la Córdoba islámica a la cristiana: conquista, repoblación y repartimiento urbano", $\mathrm{Al}$ Mulk 6: 69-94.

ESCUDERO, J. et alii (1999): "Las murallas de Córdoba (El proceso constructivo de los recintos desde la fundación romana hasta la baja Edad Media)", en Córdoba en la historia. La construcción de la urbe: 201-224. Córdoba.

FERNÁNDEZ PUERTAS, A. (1974-1975): “Bosquejo sobre la labor científica de don Félix Hernández Jiménez", Cuadernos de la Alambra 10-11: 1-9.

FUERTES, Ma.C. (1997): "La ocupación medieval del yacimiento de Cercadilla, Córdoba. Una casa califal", en Almirez 6: 161-181.

- (2002): “Aproximación al urbanismo y la arquitectura doméstica de época califal del Yacimiento de Cercadilla", Arqueología y Territorio Medieval 9: $105-125$

- (2006): “Córdoba durante el siglo XII. El abandono y ruina de los arrabales occidentales y su reconversión en espacio agrícola e industrial a través de las excavaciones de Cercadilla", en D. Vaquerizo y J.F. Murillo (eds.), El concepto de lo provincial en el mundo antiguo. Homenaje a la Prof. Pilar León, vol. II: 439-462. Córdoba.

FUERTES, M.C. e HIDALGO, R. (2001): "La evolución urbana del arrabal noroccidental de Qurțba: el yacimiento de Cercadilla", AAC 12: 159-175.

GARCÍA GÓMEZ, E. (1947): “Algunas precisiones sobre la ruina de la Córdoba Omeya", Al-Andalus 12: 267-293.

- (1965): "Notas sobre la topografía cordobesa en los “Anales de al-Hakam II" por 'Isà Rāzī", Al-Andalus 30: 329-379.

- (1967): El califato de Córdoba en el "muqtabis de Ibn Hayyan. Anales palatinos del califa de córdoba al-Hakam II, por Isa Ibn Ahmad al-Razi 971-975. Madrid.

GARCÍA GÓMEZ, E. y LÈVI PROVENÇAL, E. (1980): El siglo XI en primera persona: las "Memorias" de Abd Allah, último rey zirí de Granada destronado por los almorávides. Madrid.

- (1992): Sevilla a comienzos del siglo XII: El tratado de Ibn 'Abdūn. Sevilla.
GARCÍA BUENO, A. y MEDINA FLÓREZ, V.J. (2001): "Zócalos hispanomusulmanes en el Palacio de Orive", $A A C$ 12: 113-139.

GONZÁLEZ, M.L.; RODERO, S. y MURILLO, J.F. (2003): "Informe-Memoria de la I.A.U. en el Paseo de la Ribera (1999-2001). III. Sector de la Puerta de Martos", Anuario Arqueológico de Andalucía 2000, III/Actividades de urgencia: 237-250.

HERNÁNDEZ GIMÉNEZ, F. (1975): El alminar de "Abd Al-Rahman" III en la Mezquita mayor de Córdoba: génesis y repercusiones. Granada.

- (1985): Madinat Al-Zahra': arquitectura y decoración. Granada.

HIDALGO, R. y FUERTES, M․C. (2001): “Córdoba entre la antigüedad clásica y el Islam. Las transformaciones de la ciudad a partir de las excavaciones en Cercadilla", en F.Valdés (ed.), La islamización de la Extremadura romana. Cuadernos emeritenses 17: 223-264.

HUICI MIRANDA, A. (1969): Ibn Sahib al-Sala: AlMann bi-l-Imama. Anúbar. Valencia.

- (2000): Historia política del Imperio Almohade. 2 Tomos. Granada.

IBN HAZM, GARCÍA-GÓMEZ (trad.) (1971): El collar de la paloma: tratado sobre el amor y los amantes. Madrid.

IBN QUZMAN, M., GARCÍA-GÓMEZ (Ed.) (1972): Todo Ibn Quzman. Madrid.

LEÓN MUÑOZ, A. et alii (2004): "Informe-Memoria de la I.A.U. en el P.A. SS-4 (Entorno de la Torre de La Calahorra) (Córdoba)", Anuario Arqueológico de Andalucía 2001, III/Actividades de urgencia: 244-257.

LÉVI PROVENÇAL (1950): España musulmana, hasta la caída del Califato de Córdoba (711-1031 de J. C.). Historia de España, IV. Madrid.

- (1965): España musulmana, hasta la caída del Califato de Córdoba (711-1031 de J. C.): instituciones y vida social e intelectual. Historia de España, V. Madrid.

MARFIL, P. (1997): “Intervención arqueológica de emergencia en el $n^{\circ} 14$ de la Avenida de las Ollerías (Córdoba). 1/7/90 a 31/8/90", Anuario Arqueológico de Andalucía 1993, III/Actividades de urgencia: 149-160.

MARTÍNEZ ENAMORADO, V. (2003): Al-Andalus desde la periferia. La formación de una sociedad musulmana en tierras malagueñas (siglos VIII-X). Málaga.

MIRANDA RODRÍGUEZ, S. (2004): “Un ejemplo de historiografía cordobesa: D. Samuel de los Santos Gener", Arte, Arqueología e Historia 11: 78-81. 
MORENA, J.A. (2002): "Resultados preliminares de la Excavación Arqueológica de Urgencia realizada en el solar $n^{\circ} 63$ de la Calle Agustín Moreno de Córdoba", Anuario Arqueológico de Andalucía 1999 III/Actividades de urgencia: 150-156.

MURILLO, J.F. (1995): “Intervención arqueológica en el Palacio de Orive", Anuario Arqueológico de Andalucía 1991, III/Actividades de urgencia: 175-187.

- (1997): "Córdoba: 300-1236 d.C., un milenio de transformaciones urbanas", en G. de Boe y F. Verhaeghe (eds.), Urbanism in medieval Europe. Papers of the 'Medival Brugge 1997' Conference, vol. 1: 47-60. Zelik.

- (2003): "Informe-Memoria de la I.A.U. en el aparcamiento bajo el Vial Norte del Plan Parcial RENFE (Segunda fase)", Anuario Arqueológico de Andalucía 2000, III/Actividades de urgencia: 322-342.

MURILLO, J.F.; CARRILLO, J.R. y RUIZ LARA, D. (1999): "Intervención arqueológica en el Paseo de la Victoria (Campaña de 1993)", Anuario Arqueológico de Andalucía 1994, III/Actividades de urgencia: $69-83$.

MURILLO, J.; CASAL. Ma .T. y CASTRO, E. (2004): "Madina Qurțuba. Aproximación al proceso de formación de la ciudad emiral y califal a partir de la información arqueológica", Cuadernos de Madinna alZahra 5: 257-290.

MURILLO, J.F.; FUERTES, M.C. y LUNA, D. (1999): "Aproximación al análisis de los espacios domésticos en la Córdoba andalusí”, en P. García Verdugo y F. Acosta (coords.), Córdoba en la Historia. La construcción de la urbe: 129-154. Córdoba.

OCAÑA JIMÉNEZ, M. (1935): "Las puertas de la medina de Córdoba", Al-Andalus 3: 143-151.

- (1963): "Notas sobre la Córdoba de Ibn Hazm", AlMulk 3: 55-62.

- (1964): Repertorio de inscripciones árabes de Almería. Madrid.

- (1970): El cúfico hispano y su evolución. Madrid

- (1975): "Córdoba musulmana", en Córdoba, colonia patricia, corte de los califas, luz de occidente. León.

- (1976): Al-Hakam al-Mustansir bi-llah: el segundo califa de Córdoba. Córdoba.

- (1982): "Algo más sobre la Bāb al-Sūra de Córdoba", Al-Qantara, vol. 3, Fasc. 1-2: 447-456.

- (1986): "Arquitectos y mano de obra en la construcción de la Gran Mezquita de Occidente", Cuadernos de la Alhambra 22: 55-86.

- (1988-1990): "Inscripciones árabes fundacionales de la mezquita-catedral de Córdoba", Cuadernos de Madinat al-Zahra' 2: 9-28.
OCAÑA, M. (1989): “Torres Balbás y la Arqueología Medieval Hispano-Musulmana", Cuadernos de la Alhambra 25: 57- 64.

- (1990): "Panorámica del arte almohade en España", Cuadernos de la Alhambra 26: 91-112.

PAVÓN MALDONADO, B. (1988a): "Entre la historia y la arqueología. El enigma de la Córdoba califal desaparecida (I)", Al-Qantara IX, Fasc. 1: 169-198.

- (1988b): "Entre la historia y la arqueología. El enigma de la Córdoba califal desaparecida (II)", $A l$ Qantara IX, Fasc. 2: 403-425.

RODERO, S. et alii (2003): "Informe-Memoria de la I.A.U. en el Paseo de la Ribera (1999-2001). II. Sondeos arqueológicos efectuados en el Paseo de la Ribera con motivo de la instalación del colector marginal del Río (Plan Urban-Ribera)", Anuario Arqueológico de Andalucía 2000, III/Actividades de urgencia: 251-267.

RODRÍGUEZ TEMIÑO (2006): “Arqueología e investigación del urbanismo islámico en las ciudades andaluzas: balance de veinte años de gestión", Arqueología y territorio medieval 13: 157-173.

RUIZ LARA, D. et alii (2003): "Resultados de la intervención arqueológica realizada en el Palacio de Orive de Córdoba (1996-1998)", Anuario Arqueológico de Andalucía 2000, III/Actividades de urgencia: 299-321.

RUIZ NIETO, E. (2001):'Intervención Arqueológica de Urgencia en c/ Santa Rosa, s/n esquina con Avenida de los Almogávares (Córdoba)", Anuario Arqueológico de Andalucía 1997, III/Actividades de urgencia: $218-223$.

- (2003): "I.A.U. en la Manzana 1.1 + 1.2 del Plan Parcial RENFE", Anuario Arqueológico de Andalucía 2000, III/Actividades de urgencia: 397-402.

SANTOS GENER, S. (1950): Guía del Museo Arqueológico Provincial de Córdoba. Madrid.

- (1955): "Memoria de las excavaciones del Plan Nacional realizadas en Córdoba (1948-1950)", Informes y Memorias de la Comisaría General de Excavaciones Arqueológica, $\mathrm{n}^{\mathrm{o}}$ 31. Madrid.

TORRES BALBÁS, L. (1985): Ciudades hispano-musulmanas, 2 vol., Madrid.

— (1957): "Cementerios hispanomusulmanes", al-Andalus XXII: 131-191.

VALDÉS, F. (2004): "La Córdoba de Ibn Hazm: una lectura arqueológica de "El Collar de la Paloma"”, en J.Ma. Blázquez Martínez y A. González Blanco (coord.): Sacralidad y arqueología. Homenaje al prof. Thilo Ulbert al cumplir 65 años: 583-594.

VALLVÉ BERMEJO, J. (1986): La división territorial de la España musulmana, Madrid.

- (1990): "Manuel Ocaña Jiménez (1914-1990)", AlQantara 11, 2: 535-548. 
- (1995): "Don Emilio García Gómez, Conde de los Alixares", BRAH CXCII-Cuaderno II: 185-202.

VENTURA, A. et alii (2003): "Informe-Memoria de la I.A.U. en el aparcamiento bajo el Vial Norte del Plan Parcial RENFE (Primera fase)", Anuario Arqueológico de Andalucía 2000, III/Actividades de urgencia: $322-342$.
VICENT, A.M. (1975): "Félix Hernández", CuPAUAM 2: $31-49$

VV.AA. (1964): Homenaje al Iltmo. Sr. D. Rafael Castejón de Arizala. III Semana Nacional de Veterinaria, mayo 1964. Córdoba.

ZANÓN, J. (1989): Topografía de la Córdoba almohade a través de las fuentes árabes. Madrid.

FeCha DE ENTRADA: 28-05-2008

FECHA DE ACEPTACIÓN: 25-09-2008 